\title{
Awareness raising and educated activities for effective water savings: a case study with dual flush toilets
}

\author{
B. D. Özel \& B. B. Baykal \\ Department of Environmental Engineering, \\ Istanbul Technical University, Turkey
}

\begin{abstract}
Dual flush technology contributes to the water savings issue by introducing 3 and 6 liter flush options in contrast to conventional toilets having a typical flush volume of 9 liters. The aim of this study is to assess the public awareness and the role of educated activities toward proper use of dual flushes. Within this context, surveys were conducted in a university library where dual flush toilets had been installed. The surveys have indicated that the awareness among the users about the proper use of dual flush was only $43 \%$ at the beginning but it increased from $43 \%$ to $85 \%$ over a period of 5 months of awareness raising and educated activities. The results emphasize the critical need for public awareness, education and participation to complement technical applications in accomplishing water savings.

Keywords: dual flush toilets, education, awareness, water saving.
\end{abstract}

\section{Introduction}

The amount of fresh water that is readily accessible for direct human use is less than $1 \%$ of the world's water. Hence efficient use of water and sustainability of water resources are among priority issues of the present time. Actually, sustainability of water resources necessitates efficient use of water. The use of optimal quantity together with "fit for purpose" allocation of the quality with regard to different beneficial uses is essential within this context. As an example, $25 \%$ of domestic water supply, which normally has the quality of drinking water, is "wasted" through flushes although such high quality is not needed for toilet flushing [1]. The use of sufficient but minimal amount of flush water will help 
preserve limited water sources and achieve significant economical savings. For instance, considerable water savings could be achieved by shifting from the 3 conventional toilets using $9 \mathrm{~L}$ to dual flush toilets assigning 3 and $6 \mathrm{~L}$ of water. While 5.5 and 11 liters of water were used in the earlier models of dual flush toilets [2], current ones assign 3 and 6 liters, providing water savings of up to $60 \%$. As such, dual flush technology lends a very good tool for water savings and efficient use of water; however that would not be realized without the participation of the users. The first step in this type of participation is the awareness of consumers about this product and knowledge raising on how and also why to use the dual flushes.

The behaviour of users has crucial importance in achieving the water savings target since if dual flush toilets are not used properly, even the most advanced installation will be wasted away. The aim of this study is to assess the public awareness and the role of educated information on consumers' behaviour towards proper use dual flush toilets. This investigation carried out in a university library where dual flush toilets were installed includes three stages of surveys to assess the role of knowledge dissemination. An educated campaign about the proper use of dual flush toilets were started right after the first survey, which was followed by the second survey after 2 months and the third after three months from the second survey. SPSS software was also applied in analyzing the survey results with respect to socio-demographic variables, awareness and behaviour. The effect of educated activity on participants' awareness and behaviour has been investigated in this study.

\section{Method}

Three rounds of surveys were conducted in a university library in Istanbul, Turkey, where toilets had been installed with dual flushes of 3 and 6 liters. The library hosts an average of 2000 visitors each day with the university students and academic personnel constituting the major portion. The university library is $7 / 24$ open with the peak hours between 1 and $6 \mathrm{pm}$. The survey utilized a questionnaire concerning socio demographic variables as gender, age and education level. Respondents were also asked about their toilet use frequency in the university library. Their responses were classified as often, sometimes and almost never. Participants who almost never use the toilet were not included in data analysis. However, it was seen that major portion of university library visitors uses the toilets (the number of excluded respondents in the $1^{\text {st }}, 2^{\text {nd }}$ and $3^{\text {rd }}$ surveys were $6 \%, 8 \%$ and $4 \%$ of the respondents which corresponds to 7 out of 126,8 out of 104 and 6 out of 146, respectively). The consistency between the participants' awareness about the proper use of dual flushes and their behaviour in flushing were investigated by asking the "Do you know how to use dual flush toilets?" and "How do you use dual flush toilets?" Data were collected over a period of 5 months with three rounds of surveys.

The initial survey was conducted prior to the implementation of informative posters, thus it provides an opportunity to examine the learning effect in the second and third round of surveys which were conducted after 2 and 5 months 
from the first survey, respectively. Stickers and posters including relevant information about the function and proper use of dual flush were placed on the flush buttons and toilet cabins, respectively, Examples are presented in Figure 1, 2 and 3 (All the writings in the stickers and posters were translated from Turkish).
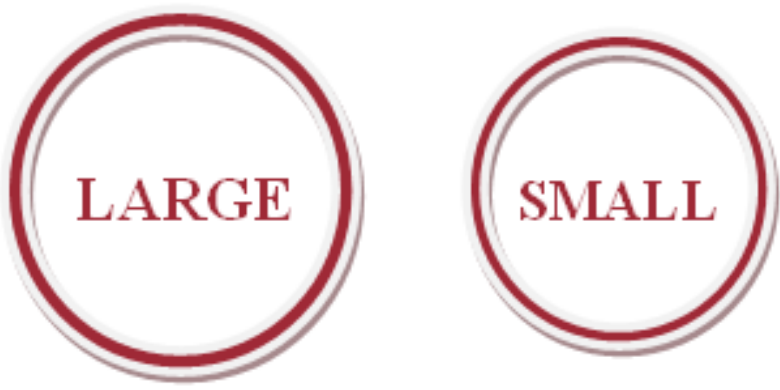

Figure 1: $\quad$ Stickers placed on flush buttons.

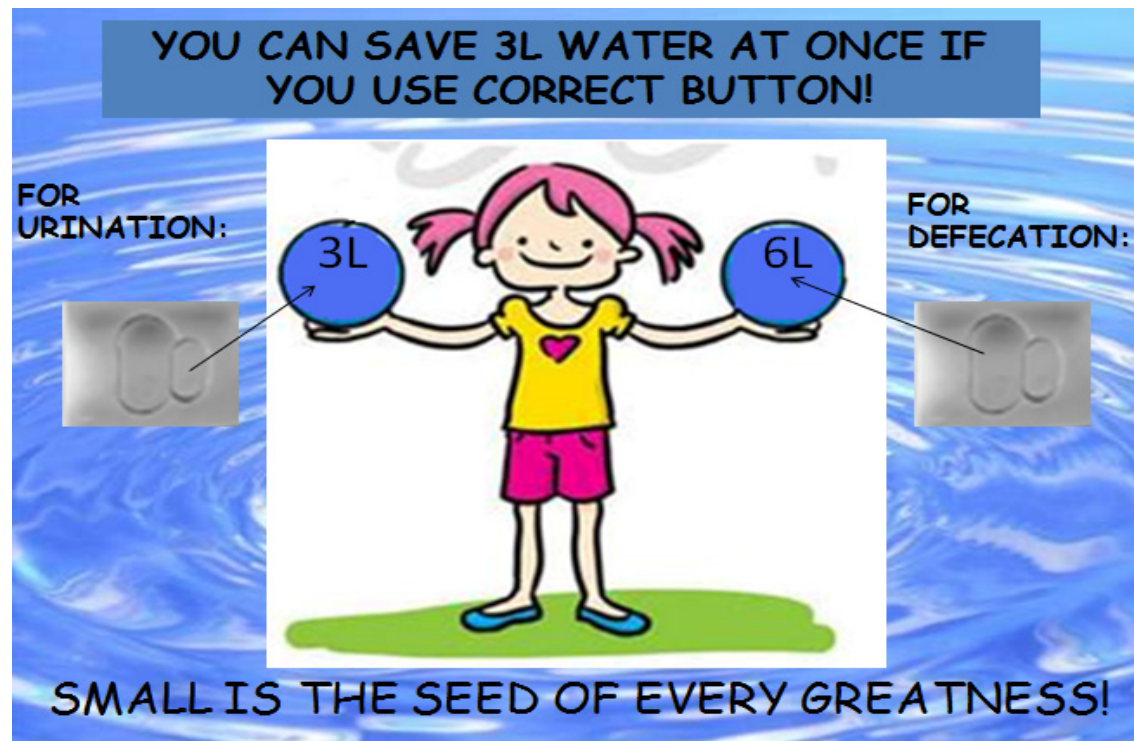

Figure 2: $\quad$ Poster hung on women's toilet cabins.

In the preparation of posters, effectiveness of communication strategies was also considered because strong demands like, "don't do it", might cause a counter-effect due to psychological reactance [3]. Therefore, messages evoking contribution, like "you can save 3L water at once if you use correct button!" 
were preferred. In a similar manner, the slogan of small is the seed of every greatness was intended to motivate people for appropriate environmental behaviour by underlying the significance of their individual acts in achieving incremental changes towards more sustainable water management.

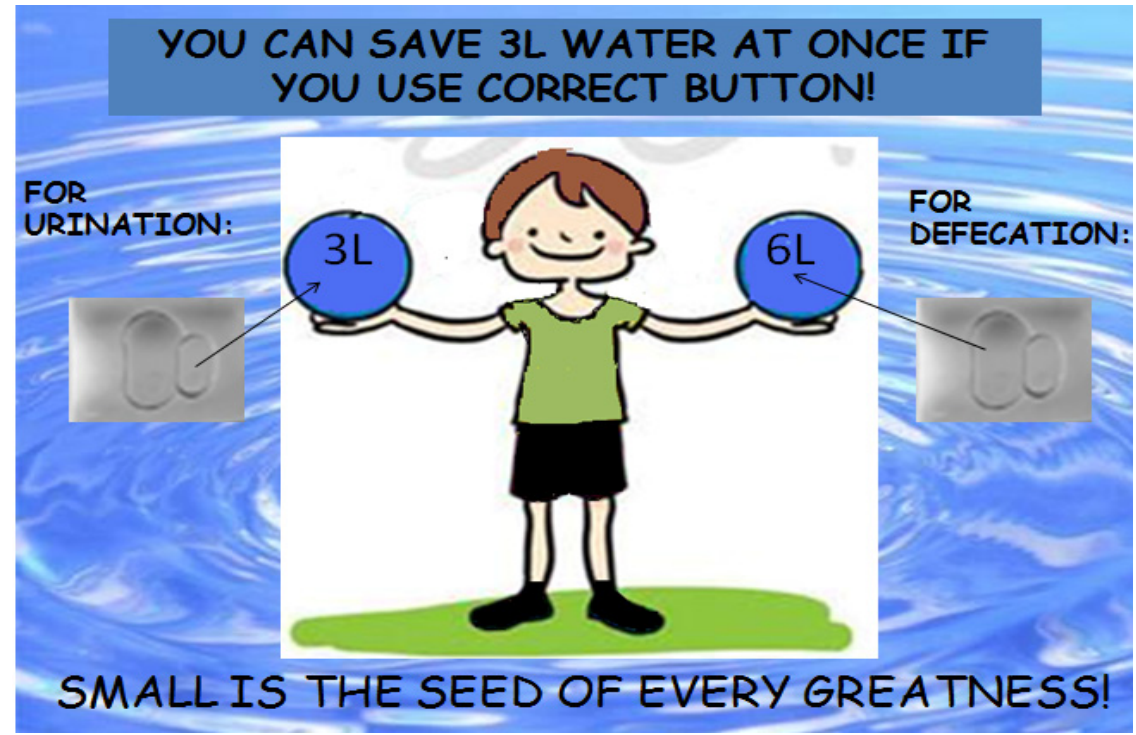

Figure 3: $\quad$ Poster hung on men toilet cabins.

The age of participants was in the range of 18-28. All the respondents had at least a high school degree and majority of them were BSc students. Among the respondents, $29 \%, 43 \%$ and $33 \%$ were female for $1^{\text {st }}, 2^{\text {nd }}$ and $3^{\text {rd }}$ surveys with total number of participants 119, 96 and 140, respectively. Data analysis was conducted by SPSS for WINDOWS 18.0 program. Chi - square test was applied to determine the differences between participants' awareness and behaviour on the proper use of dual flush toilets whereas effects of continuous variables (gender, age and education level) were determined by t-test.

\section{Results and discussion}

Figure 4 shows users' awareness toward the proper use of dual flush toilets according to the question "Do you know how to use dual flush toilets?" As may be seen, $57 \%$ of the respondents are not aware of the purpose of small (3L) and large $(6 \mathrm{~L})$ buttons. That means more than half of the users could not use the flushing system correctly. Any correct use by that group would be coincidental. Moreover, there also exists the probability that the user thinks that he knows how to operate the two buttons, which may not be reflecting the actual case. The results from the three surveys show that educated posters lead to increase in the 
awareness at the level of $77 \%$ and $85 \%$ for the second and third surveys, respectively, as opposed to $43 \%$ at the beginning which corresponds to almost twofold increase. This result indicates the importance of education required for the proper use of dual flush toilets, thus getting higher benefit from water savings.

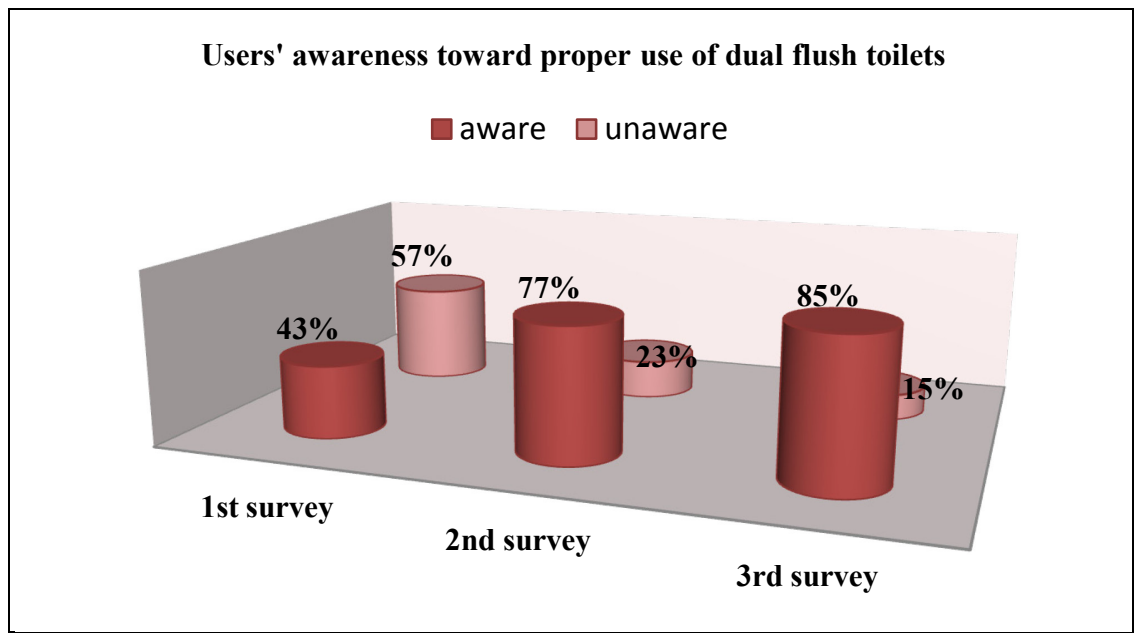

Figure 4: Users' awareness toward proper use of dual flush toilets.

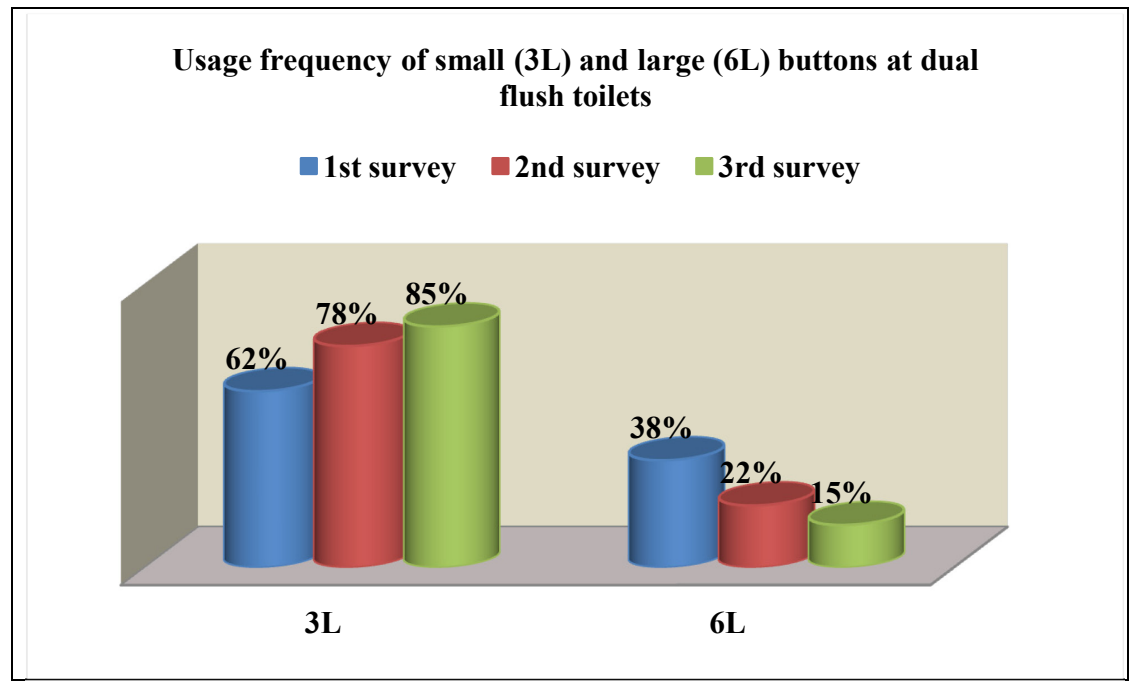

Figure 5: Frequency of small (3L) and large (6L) buttons use at dual flush toilets. 
Figure 5 represents usage frequency of small and large buttons in dual flush toilets. It is presumed that 1 out of every 6 people require actually 6 liters. Frequency of using 3L button was expected to increase for later surveys and that was supported by the findings in Figure 3 showing the use of small button has actually increased with the arising awareness.

Moreover, data interpretation of the surveys for the relation between respondents' awareness toward proper use of dual flush and their corresponding acts was performed by chi-square test showing that there is significant difference for the $95 \%$ confidence interval ( $p$ values for the three surveys; $p=0.000, p<0.05$ ) i.e., educated activities were indeed helpful. The effect of educated campaign can be translated into about $70 \%$ of water savings as shown in Table 1 . The assumption that every 1 out of every 6 people needs $6 \mathrm{~L}$ of flush water is in line with the results from the third survey. In comparison to the condition before educated activities were conducted ( $1^{\text {st }}$ survey), it seems that if dual flush toilets were used properly, about $70 \%$ of water saving could be achieved.

Table 1: Overview of questions from the three surveys.

\begin{tabular}{ll}
\hline Data Group & Question \\
\hline Personal information & Gender, age, education level \\
Frequency of usage & How often do you use the toilet in the \\
& library?/Did you use the toilet, today? \\
& If yes; Which button did you use? \\
Awareness & Do you know how to use dual flush \\
& toilets? \\
Behaviour: flushing & How do you use dual flush toilets? \\
\hline
\end{tabular}

Table 2: $\quad$ Water savings in the university library.

\begin{tabular}{lcc}
\hline & $\begin{array}{c}\text { Observed value in } \\
\text { 1st survey }\end{array}$ & Expected value \\
\hline $\begin{array}{l}\text { Usage of small water } \\
\text { volume (3L) (\%) }\end{array}$ & 62 & 85 \\
$\begin{array}{l}\text { Usage of large water } \\
\text { volume (6L) (\%) }\end{array}$ & 38 & 345 \\
$\begin{array}{l}\text { Daily flush water } \\
\text { consumption for 100 } \\
\text { persons (liter) } \\
\text { Water savings (\%) }\end{array}$ & 414 & \\
\hline
\end{tabular}

The educational level of participants is nearly homogenous with majority of BSc students. Due to these nearly homogenous samples, effect of educational level on either awareness or behaviour is not possible to reflect. Also, age of the participants is in the range of 18-38, with the mean of 22 years. The narrow range of participants' age limits the ability to investigate the effects of age on environmental behaviour. Therefore, any results regarding education level and age were dismissed. There might have been a gender differences in the 
participants' awareness, we therefore used independent t-test to test whether men and women differed in their estimation of using dual flushes. There are some studies in the literature reporting significant effects for socio-demographic variables, while many studies could not find significant effects [4]. In this study, no significant difference in awareness with respect to gender was detected, (independent t-test; $\mathrm{p}>0.05$; $\mathrm{p}$ values: $0.9,0.6$ and 0.3 for the $1 \mathrm{st}, 2 \mathrm{nd}$ and $3 \mathrm{rd}$ survey), supporting that it may be difficult to predict people's behaviour based on gender.

\section{Conclusion}

Even if dual flush toilets assigning 3 and 6 liters of flush water are not properly used, they are advantageous in water savings compared to conventional toilets having flush water volume of 9L. However, the knowledge on how to use the dual flush toilets is extremely crucial and the potential benefit expected by the investments and efforts spent on water savings can be wasted because of ignorance and careless, handling or improper behavior of users. As a result of the educated activities presented in this investigation, the awareness on the proper way of using dual flush toilets had increased from $43 \%$ up to $85 \%$ which signals the need for establishing a learning effect through the society. It is clear that if properly used, dual flush toilets provide significant water savings thus helps to preserve water resources and to promote sustainability, which will also lead to monetary savings. Therefore, it is critical to conduct educated campaigns simultaneously with the introduction of innovative installations such as dual flush toilets in achieving water saving target.

\section{References}

[1] Beler-Baykal, B., Allar, A. D., ECOSAN: Ekolojik evsel atıksu yönetimi, ITU Publishing, Su Kirlenmesi Kontrolü, 17(3), pp. 3-12, 2007 (In Turkish, with an extended summary in English)

[2] Australian Biotechnology-Innovation Website, 100 Years of Australian Innovation - Dual Flush Technology, Available at: http://www. biotechnology-innovation.com.au/innovations/instruments/flush_technology .html

[3] Hansmann, R., Scholz, R. W., A two - step informational strategy for reducing littering behavior in a cinema, Environment and Behavior, 35(6), pp. 752-762, 2003

[4] Scholz, R.W., Energy, waste, and resources in Environmental Literacy in Science and Society, pp. 169-170, 2011

[5] Nolde, E., Greywater recycling systems in Germany - results, experiences and guidelines, Water Science and Technology, 51(10), pp. 203-210, 2005

[6] Thögersen, J., Social norms and cooperation in real-life social dilemmas. Journal of Economic Psychology, 29, pp. 458-472, 2007 